\title{
The Knowledge Absorptive Capacity to Improve the Cooperation and Innovation in the Firm
}

\author{
Lourdes Saiz (D), David Pérez-Miguel(D), Miguel Ángel Manzanedo-del Campo (D) \\ Universidad de Burgos (Spain) \\ lsai_@ubu.es,dperezmigue@gmail.com,mmanz@ubu.es
}

Received: November 2017

Accepted: December 2017

\begin{abstract}
:
Purpose: The purpose of this paper is to study the absorptive capacity types in the knowledge management literature and aims to understand how companies can strength their contexts of cooperation in order to innovate.
\end{abstract}

Design/methodology/approach: A balanced panel of 1,220 firms that respond to the Survey of Business Strategies for a three-year period was used, which represents a total of 3,660 observations.

Findings: The justification of absorptive capacity typology for an innovation efficiency process. The influence of the potential and realized absorptive capacity on new products is significant and causes effects on internal research and development in diverse way. The impact of the joint ventures, suppliers' cooperation and customers' cooperation are significant on absorptive capacity.

Research limitations/implications: It would be interesting to extend the research to another innovation metrics as new organizational methods, new processes, new designs or new methods in the use of sales channels.

Practical implications: The agreement of cooperation activities constitutes an important decision for the firm's innovation. Companies must be conscious that while suppliers and customers' cooperation are relevant cooperation actions to increase the internal research and development, joint ventures and customers' cooperation are significant to the growth of the new products.

Social implications: The types of absorptive capacity and internal research and development serve as mediating mechanisms between cooperative activities and innovative performance.

Originality/value: This paper advances the literature on absorptive capacity by showing how firms use their positions of technological vigilance and management to form their capabilities, and subsequently, to enhance innovation outcomes. This study considers it is necessary to analyze the typology of the absorptive capacity that can allow managers to understand an innovation efficiency process in the cooperation context and make better decisions. The confluence of cooperation activities, absorptive capacity and organizational objectives in internal research and development obtain higher innovative results.

Keywords: knowledge management, absorptive capacity, intellectual capital, innovation, cooperation, panel model 


\section{The Construct Absorptive Capacity in the Knowledge Management and Intellectual Capital Literature}

Cohen and Levinthal (1990: page 149) published the seminal work on absorptive capacity and concluded that "firms are in fact sensitive to the characteristics of the learning environment in which they operate. Thus, absorptive capacity appears to be part of a firm's decision calculus in allocating resources for innovative activity". Since the brilliance contribution, numerous articles referred to absorptive capacity, presenting various, and often conflicting, conceptualizations (Roberts, Galluch, Dinger \& Grover, 2012). As of January 2017, the construct was cited more than 23,000 times in the management literature (Source: Google Scholar).

According to Cohen and Levinthal (1990: page 128), absorptive capacity defined as the "ability of a firm to recognize the value of new, external information, assimilate it, and apply it to commercial ends". In this point, the challenge remains how the highly cited absorptive capacity construct has been developed in the knowledge management and intellectual capital literature over the past 27 years.

From the in-depth analysis, Mariano and Walter (2015) counted only nine studies where absorptive capacity formed the theoretical base of the article in this standpoint and two articles were theoretical based (Andersén, 2012; Nieminen, 2005). These articles centred on a huge variety of areas, from organizational learning (Hagemeister \& Rodríguez-Castellanos, 2010; Kale \& Little, 2005) and knowledge management (Sun, 2010) to dynamic capabilities (Denford, 2013; Noblet, Simon \& Parent, 2011), networks (Wang \& Han, 2011) and impact on innovation (Tseng, Pai \& Hung, 2011), but did not provide a unified perspective on how future research on its capacity should be directed in the knowledge management and intellectual capital fields.

Moreover, it was found that the construct was largely underdeveloped (Noblet et al., 2011). As also suggested by Roberts et al. (2012), future studies should explore absorptive capacity as a capability more than an asset and develop a set of variables that essentially influence the level of absorptive capacity (Noblet et al., 2011). There is still much to contribute to its development and application (Hagemeister \& Rodríguez-Castellanos, 2010; Wang \& Han, 2011) and to analyse it in longitudinal research (Lowik, Kraaijenbrink \& Groen, 2016; Mariano \& Walter, 2015; Sun, 2010).

In light of such recognition about the current problem and previous research on knowledge management and intellectual capital, this study aims to examine the following two significant research questions. The primary purpose is the revision of more comprehensive conceptualizations, types and measurements of absorptive capacity as a complex construct to expand our understanding of the links between absorptive capacity and knowledge sources. The second motivation of this research is driven by the next question: "the knowledge absorptive capacity to improve the cooperation and innovation in the firm".

This paper is organized as follows. First, the construct of absorptive capacity is above introduced, providing an appropriate working framework. Second, the authors focus especially on the relationship between absorptive capacity and the sources of knowledge. Third, the discussion is then moved to the types of absorptive capacity in the contexts of cooperation. Fourth, the conclusions and limitations are discussed. Finally, the references and appendixes complete this article.

\section{The Relationship Between the Sources of Knowledge and Absorptive Capacity with the Innovation Performance}

The firm's absorptive capacity has been strongly linked to its performance and long-term survival (Cohen \& Levinthal, 1989, 1990). Innovation performance is a fundamental source of competitive advantage and is affected both by the origins of the existing knowledge that is combined to generate innovation and by how economic actors search for new knowledge (Capaldo \& Messeni, 2015).

We summarize the most relevant contributions of the specialized literature. Aribi and Dupouët (2016) suggest that, far from being linear, the process displays several feedback loops, both within and between each phase of absorption. Lowik et al. (2016) determine that managers who seek to improve knowledge-intensive teams' performance are advised to take a holistic approach and to consider the triad of team absorptive capacity: team members' individual absorptive capacity, mechanisms that enable and motivate knowledge integration. The authors 
show how a configurational approach deepens understandings of the micro-foundations of team absorptive capacity.

Rezaei and Darwish (2016) reveal the complex interplay between the antecedents of absorptive capacity and demonstrate that these antecedents vary, comprising exploratory, transformative and exploitative learning processes. Grandinetti (2016) utilizes this construct to clarify the difference between Small and Medium-Sized Enterprises (SMEs) and larger corporations from the knowledge management standpoint. The author argues that the difference is generally attributed, somewhat superficially, to the fact that SMEs rely more heavily on external sources of knowledge. This would be true if such external sources were always used in lieu of internal knowledge creation processes, but large companies also nourish their internal knowledge production capacity through equally robust knowledge absorption channels.

Capaldo and Messeni (2015) studied the Research and Development (R\&D) alliances and found that whereas the integration of geographically distant knowledge and of organizationally proximate knowledge in $\mathrm{R} \& \mathrm{D}$ alliances are negatively related to the alliance innovative performance, search span positively moderates both relationships. The researchers conclude that enterprises participating in $R \& D$ alliances should integrate geographically distant but organizationally proximate knowledge. By doing so, firms take advantage of the diversity and novelty that characterizes geographically distant knowledge, while preserving considerable levels of relative absorptive capacity that are needed for them to understand, internalize, and effectively use partners' knowledge from different domains.

Yoo, Sawyerr and Tan (2015) support the existence of direct effects of environmental and firm-specific factors as well as the moderating effects of the external environment on firm-specific factors. Díaz-Díaz and Saá-Pérez (2014) confirm that the type of knowledge source used, internal or external, constitutes an important decision, and reveal that it is necessary to identify each of the possible sources likely to be used, since their influence on innovation can differ depending on the importance of the internal knowledge base. The policy to renew knowledge in order to update a firm's capacity to innovate is an essential executive decision, which has significant consequences on the knowledge management process as several authors have confirmed (Fixson \& Lee, 2012; Messeni, Rotolo \& Albino, 2012; Sun, 2010).

With regard to the use of internal knowledge sources, the authors' findings confirm that the absorptive capacity increases innovation up to a certain point, after which this positive effect may decline. It can be said that firms with an excess of internal knowledge do not obtain better innovative results because over time, firms tend to enter a state of inertia and need external sources of knowledge to renew their knowledge. Because "the confluence of excessive internal knowledge and organizational inertia may make the relationship between the firm's absorptive capacity and innovation non-linear" (Díaz-Díaz \& Saá-Pérez, 2014: page 440).

Paulsen and Hjertø (2014) suggest that individual and group autonomy, along with individual experiences of absorptive capacity, supports complementarily inter-organizational knowledge transfer. Noblet et al. (2011) emphasize the role of trust in the growth of its capacity. Wang and Han (2011) centre on environmental conditions and the absorptive capacity-innovation performance relationship, with a special attention on researching the importance of the network structure.

Sun (2010) suggests that five key organizational themes influenced the processes of acquisition, creation, utilization and sharing and call for further investigations of the exploration-exploitation tension. Nieminen (2005) asks for a holistic understanding of the effects of the relationship context and the partners. Kale and Little (2005) analyze the organizational learning in developing countries and exploration of institutional environment for organizational learning.

\section{The Typology of Absorptive Capacity in the Contexts of Cooperation for the Innovation Efficiency}

From the standpoint of the economics of innovation, $R \& D$ alliances and cooperation can be appreciated as the process of spillover which is an economical term to represent knowledge dissemination. Unlike physical assets, knowledge is hard to appropriate and easily diffused in the economy through various channels (Fukugawa, 2015). 
According to Cohen and Levinthal (1990), the user of knowledge cannot benefit from spillover from the provider of knowledge for free. What is fundamental is absorptive capacity, which raises to the user's internal re-sources to identify, value, assimilate and exploit external sources of knowledge.

One of the main ideas in absorptive capacity literature is that "an organization's absorptive capacity will depend on the absorptive capacities of its individual members" (Cohen \& Levinthal, 1990: page 131). For example, Fukugawa (2015) shows how the concept of absorptive capacity can be applied to teaching in English as a spillover channel. The author supposes that a lecture is a mode of knowledge transfer and students are assumed to retain a certain level of absorptive capacity through intellectual and linguistic skills which constitute their 'absorptive capacity' and enable them to acquire 'new knowledge' from 'spillover pool'.

For the participants to make the most of external knowledge, they need to accumulate absorptive capacity through their own 'learners' comprehension and linguistic skills. No matter how large the spillover pool is, it does not make sense if the user has no absorptive capacity (Fukugawa, 2015). Once we can understand it, as a typical application of absorptive capacity of Cohen and Levinthal (1990) to particular field and we can observe that capacity as a collective construct.

The review of the more relevant research determines that Van der Heiden, Pohl, Mansor and Van Genderen (2016) differentiate the "necessitated" absorptive capacity as a dynamic capability. On the other side, Zahra and George (2002) distinguish two types of absorption capacity: The potential and realized. In this line, we can find examples of its terminology. For instance, Ojo, Raman and Chong (2016) concentrate on "potential absorptive capacity" to elucidate the factors that underlie the differences in individual absorptive capacity within the context of joint project teams. Martelo-Landroguez and Cegarra-Navarro (2014) examine the significance of knowledge transfer and knowledge storage/retrieval processes as bridges between "potential absorptive capacity" and "realized absorptive capacity" and its effects on the application of knowledge. The researchers reveal that a "realized absorptive capacity" is unlikely without being fostered by the transference and storage of new knowledge and it therefore requires empowerment by its facilitating factors.

That is possible because few studies aim to describe of how its capacity works (Cohen \& Levinthal, 1990; Lane, Koka \& Pathak, 2006; Todorova \& Durisin, 2007; Volberda, Foss \& Lyles, 2010; Zahra \& George, 2002). Aribi and Dupouët (2016) resume the next agreements. First, all authors present absorptive capacity as a process that unfolds over time and that may involve different actors of the firm. Second, despite the differences between models, everybody can distinguish three main phases: exploration, transformation, and exploitation.

Based on the knowledge management and notion of organizational absorptive capacity as a meta-routine capacity (Paulsen \& Hjertø, 2014; Sun, 2010; Van der Heiden et al., 2016) and surrounded in the contexts of cooperation, the typology of absorptive capacity represented need to be connected with the organizational objective settings. When the sources are external, the absorptive capacity allows employees the introduction of significant data and tracks the potential information around its boundaries. In order to obtain a realized capacity is required a potential capacity. The more potential can mean a greater realized percentage. The well-performance absorptive capacity firm converts its potential in realized actions.

Taking into account these considerations, the following hypothesis can be stated as:

\section{H1. The cooperation activities have a positive and significance relation with the potential absorptive capacity.}

H2. The cooperation activities have a positive and significance relation with the realized absorptive capacity.

H3. The potential absorptive capacity has a positive and significance relation with the realized absorptive capacity.

Furthermore, the company workers should clearly identify what the goals required to improve the internal R\&D projects are. We consider that the company when learns is a profitless process unless it is related with instruments to improve. While the learning is an accumulative process without end, the useful absorptive capacity depends on the establishing of objectives. The absorptive capacity finishes when the objective is satisfied and thus more learning is not necessary. 
Taking into account these considerations, the following hypothesis can be indicated as:

H4. The potential absorptive capacity has a positive and significance relation with the organizational objectives.

H5. The realized absorptive capacity has a positive and significance relation with the organizational objectives.

H6. The realized absorptive capacity has a positive and significance relation with the innovation efficiency.

H7. The organizational objectives have a positive and significance relation with the innovation efficiency.

For contributing to the literature, the Figure 1 shows the proposed model and we can observe the typology of absorptive capacity as a potential method to con-tribute to the innovation improvement. Thus, this contribution opens the black box of the absorptive capacity that permit the managers take consciousness of the potential advantages to strengthen the cooperation contexts.

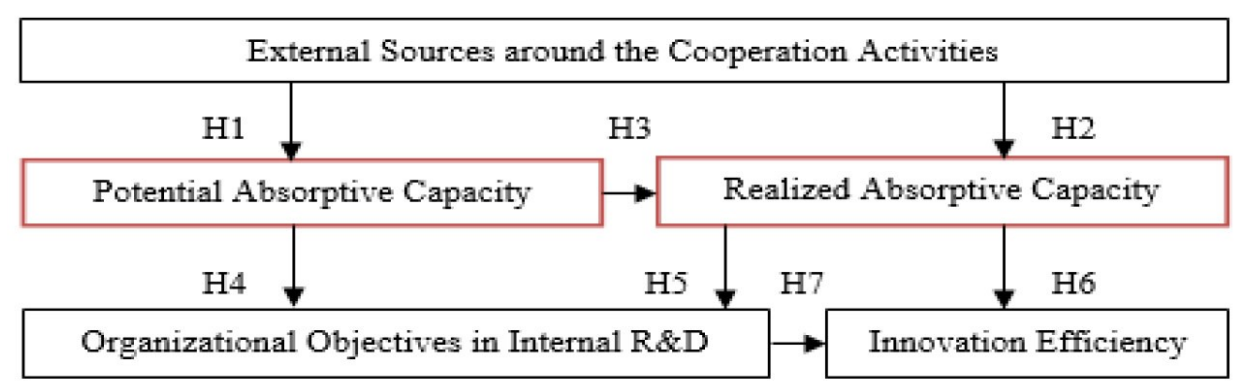

Figure 1. Model of types of absorptive capacity for the innovation efficiency

\section{Methodology}

\subsection{Data and Sample}

With the purpose of testing the previously planned hypotheses, an empirical study was organized on the basis of the Spanish industrial firms that responded to the Survey of Business Strategies (SBS). The SBS has been managed by the SEPI Foundation in cooperation with the Spanish Ministry of Science and Technology since 1990 and aims to examine the evolution of the strategies of Spanish industrial firms. This survey represents an unbalanced panel since some companies cease to provide information while others continue to do so every year. In particular, it composes a mixed data set in which a random sample of small firms (with fewer than 200 employees) is established, while for large corporations (with more than 200 employees) the sampling is more extensive. The replies are voluntary, respondents are guaranteed confidentiality and the survey would be used to form a government policy. The response rates for different sectors and sizes are consistent with the overall response pattern. Therefore, one of the points that differentiate the SBS from other data sources is its explicit objective of generating information with a panel structure. All the information incorporated in the SBS is subjected to validation and logical consistency controls.

To carry out this research, and after data screening, a sample included of a balanced panel of 5,566 firms. There were considered only those organizations that have consistently responded to the survey in the analysis period, 2010-2015 to determine a sample of complete panel of companies. Thus, 1.220 firms for a three-year period was used, which represents a total of 3,660 observations. The sampling error was 0.2457 with a confidence level of 95\%. The sample was stratified by 20 Standard Industrial Classification (SIC) codes. Table 1 summarizes the industries comprised in the sample. 


\begin{tabular}{|l|r|}
\hline Number of firms in each year & \\
\hline Low technology industry & 563 \\
\hline Meat industry & 47 \\
\hline Food and tobacco products & 156 \\
\hline Beverages & 29 \\
\hline Textiles and clothing & 80 \\
\hline Leather and footwear & 33 \\
\hline Wood industry & 36 \\
\hline Paper & 53 \\
\hline Editing and graphic arts & 48 \\
\hline Furniture & 50 \\
\hline Other manufacturing products & 31 \\
\hline Medium-low technology industry & 339 \\
\hline Rubber and plastic products & 70 \\
\hline Non-metallic mineral products & 84 \\
\hline Metallurgy & 44 \\
\hline Metal products & 141 \\
\hline Medium-high technology industry & 251 \\
\hline Chemical products & 87 \\
\hline Machinery and mechanical equipment & 73 \\
\hline Motor vehicles & 62 \\
\hline Other transport equipment & 29 \\
\hline High technology industry & 67 \\
\hline Office and data processing machines; precision and optical instruments & 20 \\
\hline Machinery; electrical and electronic goods & 47 \\
\hline Total Firms & 1,220 \\
\hline & \\
\hline
\end{tabular}

Table 1. Descriptive of industry in the sample

\subsection{Variables}

The constructs were treated through an iterative process, using insights from previous literature and follow mainly to Beneito, Rochina and Sanchis (2011), Díaz-Díaz and Saá-Pérez (2014), Díaz-Díaz, Aguilar-Díaz and Saá-Pérez (2006), Segarra-Ciprés, Bou-Llusar and Roca-Puig (2012). This section describes how constructs were measured from the SBS questionnaire.

Dependent variable. The dependent variable in this investigation is the organization's product innovation, which is measured in terms of the flow of output. The variable (Innovation Efficiency) is measured as the number of new products obtained by the firm each year.

Explanatory variables. The External Sources around the Cooperation Activities are measured by three variables. The first variable includes the establishment of joint technological ventures (Joint Ventures). The next variables reflect the firm's establishment of technological collaboration agreements with its customers (Customers' Cooperation) or with its suppliers (Suppliers' Cooperation). These actions do not entail such high commitment and involvement from the companies as joint ventures do. The Internal R\&D Effort is measured as the logarithm of the internal $\mathrm{R} \& \mathrm{D}$ expenditure in each year. The other two variables were obtained from a confirmatory factor analysis. The first factor, Technological Vigilance as a measure of Potential Absorptive Capacity, comprises of three 
items that reflect the evaluation of alternative technologies by firms, the evaluation of technological change and the contracting of outside consultants as a mechanism for obtaining information about technology. The component of Table 2 achieved $78.1 \%$ of the total variance explained.

\begin{tabular}{|c|c|c|c|c|c|c|}
\hline \multirow[b]{3}{*}{ Component } & \multirow{2}{*}{\multicolumn{3}{|c|}{ Initial Eigenvalues }} & \multicolumn{3}{|c|}{ Total Variance Explained } \\
\hline & & & & Extra & ction Sums of Squ & ed Loadings \\
\hline & Total & $\%$ of variance & Cumulative $\%$ & Total & $\%$ of variance & Cumulative $\%$ \\
\hline 1 & 2.345 & 78.153 & 78.153 & 2.345 & 78.153 & 78.153 \\
\hline 2 & .460 & 15.345 & 93.498 & & & \\
\hline
\end{tabular}

Extraction Method: Principal Component Analysis.

Table 2. Factor analysis of Technological Vigilance

The second factor, Technological Management as a measure of Realized Absorptive Capacity, covers the existence of a firm's technology management or committee, the preparation of a plan and the measurement of results obtained in this management process. The component of Table 3 reached $82.5 \%$ of the total variance explained.

\begin{tabular}{|c|c|c|c|c|c|c|}
\hline \multirow[b]{3}{*}{ Component } & \multirow{2}{*}{\multicolumn{3}{|c|}{ Initial Eigenvalues }} & \multicolumn{3}{|c|}{ Total Variance Explained } \\
\hline & & & & \multicolumn{3}{|c|}{ Extraction Sums of Squared Loadings } \\
\hline & Total & $\%$ of variance & Cumulative $\%$ & Total & $\%$ of variance & Cumulative $\%$ \\
\hline 1 & 2.477 & 82.554 & 82.554 & 2.477 & 82.554 & 82.554 \\
\hline 2 & .362 & 12.063 & 94.618 & & & \\
\hline
\end{tabular}

Table 3. Factor analysis of Technological Management

Control variables. The control variables included in this research are: Size, measured as the logarithm of number of employees. Age calculated as the number of years since the company's founding and the firm's Return on Assets, which is measured in the same year because we try to understand the immediate effects of absorptive capacity. The differences between industries, in terms of economic and technological opportunities, result in appropriability or market concentrations, measured through four dummy variables that represent the Industry's Technological Intensity; Location calculated as a dummy variable, which takes the value of 1 if the firm responds affirmatively to the question about national or international markets; Annual time dummies to control macroeconomic trends such as economic downturns and periods of technological growth that could affect overall innovation probability. Two dummy variables, the first being Market Stable, which takes the value of 1 if the firm responds affirmatively to the question about stable markets, and 0 if the markets are expanding; and the second, Market in Recession takes the value 1 if the firm responds affirmatively about recessive markets, and 0 if it does not. In addition, Table 4 condenses the variables used in this research.

In order to provide more information about the different variables used in this study, Table 5 gives bivariate correlations, as well as the summary statistics. 


\begin{tabular}{|c|c|}
\hline Variable & Description \\
\hline Innovation efficiency & Innovation: number of new products obtained by the firm in each year. \\
\hline Organization objectives & Internal R\&D effort: logarithm of the internal $R \& D$ expenditure in each year. \\
\hline Potential absorptive capacity & $\begin{array}{l}\text { Technological vigilance: Factor dimension that comprises three items that reflect the } \\
\text { evaluation of alternative technologies, the evaluation of technological change and the } \\
\text { contracting of outside consultants in each year. }\end{array}$ \\
\hline Realized absorptive capacity & $\begin{array}{l}\text { Technological management: Factor dimension that reflects the existence of a technology } \\
\text { management or committee, the preparation of a plan and the measure of results obtained in } \\
\text { this management process in each year. }\end{array}$ \\
\hline Cooperative activities & $\begin{array}{l}\text { Joint ventures: the firm's establishment of joint technological ventures. } \\
\text { Customers' cooperation: the establishment of technological collaboration agreements with its } \\
\text { customers in each year. } \\
\text { Suppliers' cooperation: the establishment of technological collaboration agreements with its } \\
\text { suppliers in each year. }\end{array}$ \\
\hline Control & $\begin{array}{l}\text { Size: logarithm of the firm's employees. } \\
\text { Age: number of years since the firm's founding. } \\
\text { ROA: firm's return on assets in each year. } \\
\text { Location: value } 1 \text { if the firm competes in national or international markets, and } 0 \text { if it does } \\
\text { not. } \\
\text { Market stable: value of } 1 \text { if the firm responds affirmatively to the question about stable } \\
\text { markets, and } 0 \text { if the markets are expanding. } \\
\text { Market in recession: value } 1 \text { if the firm responds affirmatively about recessive markets, and } 0 \\
\text { if it does not. } \\
\text { Industry's technological intensity: four Dummy variables that represent the industry's } \\
\text { technological intensity (low, medium-low, medium-high, high). } \\
\text { Years: three annual time dummies that represent the year }(2010,2014,2015) \text {. }\end{array}$ \\
\hline
\end{tabular}

Table 4. Description of the variables

\begin{tabular}{|c|c|c|c|c|c|c|c|c|c|}
\hline \multicolumn{10}{|c|}{ Correlations } \\
\hline Variables & 1. & 2. & 3. & 4. & 5. & 6. & 7. & 8. & 9. \\
\hline 1. Innovation & 1 & & & & & & & & \\
\hline 2. Internal R\&D effort & $.153^{* *}$ & 1 & & & & & & & \\
\hline 3. Tech-vigilance & $.099 * *$ & $.500 * *$ & 1 & & & & & & \\
\hline 4. Tech-management & $.159 * *$ & $.763^{* *}$ & $.594 * * *$ & 1 & & & & & \\
\hline 5. Joint ventures & $.081 * *$ & $.212^{* *}$ & $.216^{* *}$ & $.260 * *$ & 1 & & & & \\
\hline 6. Customers' cooperation & $.122^{* *}$ & $.572 * *$ & $.429 * *$ & $.541 * *$ & $.200 * *$ & 1 & & & \\
\hline 7. Suppliers' cooperation & $.117^{* *}$ & $.640 * *$ & $.515^{* *}$ & $.623^{* *}$ & $.222^{* *}$ & $.681 * *$ & 1 & & \\
\hline 8. Size & $.101^{* *}$ & $.515^{* *}$ & $.427 * *$ & $.502^{* *}$ & $.214^{* *}$ & $.362^{* *}$ & $.447 * *$ & 1 & \\
\hline 9. Age & .022 & $.203^{* *}$ & $.137 * *$ & $.188^{* *}$ & $.063^{* *}$ & $.150^{* *}$ & $.158^{* *}$ & $.239 * *$ & 1 \\
\hline 10. ROA & -.005 & $-.034^{*}$ & -.026 & -.031 & -.009 & -.022 & -.027 & $-.069 * *$ & -.023 \\
\hline 11. Low TI & -.019 & $-.208^{* *}$ & $-.070^{* *}$ & $-.160 * *$ & $-.077 * *$ & $-.206^{* *}$ & $-.157 * *$ & $-.186^{* *}$ & -.005 \\
\hline 12. Medium-low TI & -.026 & $-.080^{* *}$ & $-.082 * *$ & $-.100^{* *}$ & -.025 & $-.045^{* *}$ & $-.053 * *$ & $-.055^{* *}$ & $-.058^{* *}$ \\
\hline 13. Medium-high TI & .016 & .263 & .121 & .244 & .105 & .226 & .186 & .249 & $.070^{* *}$ \\
\hline 14. High TI & $.064^{* *}$ & $.144^{* *}$ & $.099 * *$ & $.113^{* *}$ & $.033^{*}$ & $.139 * *$ & $.117 * *$ & $.074^{* *}$ & .001 \\
\hline 15. Market stable & -.026 & $-.040^{*}$ & $-.059 * *$ & $-.040 *$ & .006 & $-.046^{* *}$ & $-.045^{* *}$ & .028 & .003 \\
\hline 16. Market in recession & .005 & $-.069 * *$ & -.029 & $-.076^{* *}$ & -.029 & $-.062^{* *}$ & $-.056^{* *}$ & $-.137 * *$ & -.012 \\
\hline
\end{tabular}




\begin{tabular}{|c|c|c|c|c|c|c|c|c|c|}
\hline \multicolumn{10}{|c|}{ Correlations } \\
\hline 17. Location & .021 & $.196^{* *}$ & $.132 * *$ & $.208^{* *}$ & $.109 * *$ & $.146^{* *}$ & $.168^{* *}$ & $.406^{* *}$ & $.075^{* *}$ \\
\hline Variables & 10. & 11. & 12. & 13. & 14. & 15. & 16. & Mean & SD \\
\hline 1. Innovation & & & & & & & & 1.140 & 7.586 \\
\hline 2. Internal R\&D effort & & & & & & & & 1.375 & 2.074 \\
\hline 3. Tech-vigilance & & & & & & & & .598 & .980 \\
\hline 4. Tech-management & & & & & & & & .606 & 1.028 \\
\hline 5. Joint ventures & & & & & & & & .030 & .163 \\
\hline 6. Customers' cooperation & & & & & & & & .170 & .376 \\
\hline 7. Suppliers' cooperation & & & & & & & & .210 & .407 \\
\hline 8. Size & & & & & & & & 1.800 & .625 \\
\hline 9. Age & & & & & & & & 32.070 & 19.174 \\
\hline 10. ROA & 1 & & & & & & & .0002 & .0039 \\
\hline 11. Low TI & .029 & 1 & & & & & & .460 & .498 \\
\hline 12. Medium-low TI & -.005 & $-.573^{* *}$ & 1 & & & & & .280 & .448 \\
\hline 13. Medium-high TI & -.018 & $-.471 * *$ & $-.317 * *$ & 1 & & & & .210 & .405 \\
\hline 14. High TI & -.022 & $-.223^{* *}$ & $-.150 * *$ & $-.123^{* *}$ & 1 & & & .050 & .228 \\
\hline 15. Market stable & $.040 *$ & $.035^{*}$ & -.031 & .002 & -.019 & 1 & & .520 & .500 \\
\hline 16. Market in recession & $-.041 *$ & .017 & $.033^{*}$ & $-.063 * *$ & .011 & $-.665^{* *}$ & 1 & .290 & .453 \\
\hline 17. Location & -.017 & $-.065^{* *}$ & -.011 & $.107 * *$ & -.028 & .006 & -.026 & .080 & .274 \\
\hline
\end{tabular}

Table 5. Correlation matrix and descriptive statistics

\subsection{Econometric specifications}

To test the hypotheses, a regression lineal model that analyses the relationship between the types of absorptive capacity and organization objectives as well as the cooperation activities effect was specified. The variables were significant at the probability p, $0.10(*), \mathrm{p}, 0.05(* *)$ and $\mathrm{p}, 0.01(* *))$ level. Additionally, due to the fact that the principal dependent variable, the "Innovation efficiency", is a non-negative, integer count variable, a negative binomial panel estimation is used. We followed the recommendation of Díaz-Díaz and Saá-Pérez (2014) and, for such data, count models provide an econometric improvement over the classical linear regression models because this type of data violates one of the main assumptions of the classical linear regression model. The negative binomial model is an extension of the Poisson model and allows for management of over-dispersion. The Lagrange multiplier test of over-dispersion to test this supposition was conducted and the results revealed that a negative binomial model provides a significantly better fit than the Poisson model, as will be seen in the Table 11 . Moreover, in order to control for unobserved time-constant heterogeneity, which may affect a firm's innovative performance, we have estimated a negative binomial panel data model. The proposed models were estimated using the econometric package SPSS v.24.

\subsection{Results}

First, to ensure that multicollinearity is not a problem in the models, variance inflation factors (VIFs) for variables were calculated. The VIF levels are below the critical threshold of 10, indicating that multicollinearity does not contaminate the results (O'Brian, 2007). The mean VIF-values are below 3 and the mean VIF-value in the study is 1,659 , as shown in Table 6 . Therefore, no serious concern about multicollinearity was raised. 


\begin{tabular}{|l|r|l|r|}
\hline Variables & \multicolumn{1}{|l|}{ VIF } & Variables & \multicolumn{1}{l|}{ VIF } \\
\hline Joint ventures & 1.093 & Medium-low tech industry & 1.176 \\
\hline Suppliers' cooperation & 2.428 & Medium-high tech industry & 1.304 \\
\hline Customers' cooperation & 2.051 & High tech industry & 1.116 \\
\hline Technological vigilance & 1.677 & Market stable & 1.816 \\
\hline Technological management & 2.930 & Market in recession & 1.888 \\
\hline Internal R\&D effort & 2.867 & Location & 1.209 \\
\hline Size & 1.790 & 2014 & 1.377 \\
\hline Age & 1.086 & 2015 & 1.400 \\
\hline ROA & 1.009 & VIF average value & 1.659 \\
\hline
\end{tabular}

Table 6. Collinearity diagnostic: Variance inflation factors (VIFs)

Second, to analyze the influence of cooperation activities on types of absorptive capacity several regression models have been estimated. The models shown in Tables 7 to 10 consider respectively "Technological vigilance", "Technological management", "Internal R\&D effort" as the dependent variables. Model I only considers the influence of the control variables on a dependent variable. The main effects of cooperation activities to Model II were added. The firm's absorptive capacity is introduced in Models III and IV.

With the aim of testing hypothesis $\mathrm{H} 1$ and $\mathrm{H} 2$ related with the relationship between external sources and absorptive capacity, the dependent variables were included in the models. As shown in Model II of Table 7 and Table 8, when the establishment of joint ventures and the agreements with suppliers and customers are added, models fit increases in a significant way.

The results of Model II of Table 7 and Table 8 show a positive and significant influence of the three actions that form the cooperation activities ( $\mathrm{p}, 0.01$ ). Similarly, the results of Model III of Table 8 reveal a positive effect of cooperation activities on technological management, as well as the technological vigilance (p, 0.01$)$, in order to test H3.

With the intention of testing hypothesis $\mathrm{H} 4$ and $\mathrm{H} 5$ related with the types of absorptive capacity and organizational objectives around internal R\&D, the cooperation activities were included in the Model II of Table 9. These actions are positive and significant on dependent variable.

Then, the technological vigilance was incorporated in the Model III of Table 10. In this step, the results show a positive and significant influence of the technological vigilance (p, 0.01). In the next step, the technological management was included in the Model IV of Table 10 and while the results show a positive and significant influence of this variable ( $p, 0.01)$, the technological vigilance loses the significance and, thus, gives more support for $\mathrm{H} 3$ when the absorptive capacity explains the relationship with the internal R\&D effort. Furthermore, the Adjusted R-Squared of Model IV raises to 0.650 of explained variance.

Regarding control variables, results reveal that a firm's size and age have a positive and significant effect on internal $\mathrm{R} \& \mathrm{D}$ effort. Moreover, firms in sectors with a medium-low, medium-high and high technological intensity have a positive effect on internal $R \& D$ effort. 


\begin{tabular}{|c|c|c|c|c|}
\hline \multirow[b]{2}{*}{ Variables } & \multicolumn{2}{|c|}{ Model I } & \multicolumn{2}{|c|}{ Model II } \\
\hline & Beta & Std error & Beta & Std error \\
\hline Constant Controls & $-0.518^{* * *}$ & 0.068 & $-0.206^{* * *}$ & 0.063 \\
\hline Size & $0.676^{* * *}$ & 0.028 & $0.399 * * *$ & 0.028 \\
\hline Age & $0.002^{* * *}$ & 0.001 & 0.000 & 0.001 \\
\hline $\mathrm{ROA}$ & 1.871 & 3.792 & 0.924 & 3.458 \\
\hline Medium-low tech industry & $-0.093^{* * *}$ & 0.036 & $-0.126^{* * *}$ & 0.033 \\
\hline Medium-high tech industry & 0.016 & 0.041 & $-0.123^{* * *}$ & 0.038 \\
\hline High tech industry & $0.255^{* * *}$ & 0.068 & 0.024 & 0.063 \\
\hline Market stable & $-0.182^{* * *}$ & 0.040 & $-0.100^{* * *}$ & 0.037 \\
\hline Market in recession & -0.069 & 0.045 & -0.009 & 0.041 \\
\hline Location & $-0.174 * * *$ & 0.060 & $-0.171^{* * *}$ & $0.055 \mathrm{C}$ \\
\hline Dummies years & Yes & & Yes & \\
\hline \multicolumn{5}{|l|}{ Main effects } \\
\hline Joint ventures & & & $0.433^{* * *}$ & 0.086 \\
\hline Suppliers' cooperation & & & $0.319^{* * *}$ & 0.050 \\
\hline Customers' cooperation & & & $0.745^{* * *}$ & 0.048 \\
\hline Adjusted R-Squared & 0.193 & & 0.329 & \\
\hline $\mathrm{F}$ & $77.554^{* * *}$ & & $124.192^{* * *}$ & \\
\hline
\end{tabular}

Table 7. Lineal regression on technological vigilance

\begin{tabular}{|c|c|c|c|c|c|c|}
\hline \multirow[b]{2}{*}{ Variables } & \multicolumn{2}{|c|}{ Model I } & \multicolumn{2}{|c|}{ Model II } & \multicolumn{2}{|c|}{ Model III } \\
\hline & Beta & Std error & Beta & Std error & Beta & Std error \\
\hline Constant Controls & $-0.753^{* * *}$ & 0.067 & $-0.365^{* * *}$ & 0.059 & $-0.300 * * *$ & 0.055 \\
\hline Size & $0.724 * * *$ & 0.028 & $0.378^{* * *}$ & 0.026 & $0.253^{* * *}$ & 0.025 \\
\hline Age & $0.004 * * *$ & 0.001 & $0.002^{* * *}$ & 0.001 & $0.002^{* * *}$ & 0.001 \\
\hline $\mathrm{ROA}$ & 1.623 & 3.746 & 0.438 & 3.198 & 0.148 & 3.008 \\
\hline Medium-low tech industry & -0.027 & 0.036 & $-0.069^{* * *}$ & 0.030 & -0.030 & 0.029 \\
\hline Medium-high tech industry & $0.333^{* * *}$ & 0.040 & $0.155^{* * *}$ & 0.035 & $0.194 * * *$ & 0.033 \\
\hline High tech industry & $0.430 * * *$ & 0.067 & $0.135^{* * *}$ & 0.058 & $0.127 * * *$ & 0.055 \\
\hline Market stable & $-0.208^{* * *}$ & 0.039 & $-0.105^{* * *}$ & 0.034 & $-0.073^{* * *}$ & 0.032 \\
\hline Market in recession & $-0.173^{* * *}$ & 0.045 & $-0.096^{* * *}$ & 0.038 & $-0.093^{* * *}$ & 0.036 \\
\hline Location & 0.044 & 0.059 & 0.048 & 0.050 & $0.101^{* * *}$ & 0.048 \\
\hline Dummies years & Yes & & Yes & & Yes & \\
\hline \multicolumn{7}{|l|}{ Main effects } \\
\hline Joint ventures & & & $0.512^{* * *}$ & 0.080 & $0.377 * * *$ & 0.075 \\
\hline Suppliers' cooperation & & & $0.902^{* * *}$ & 0.044 & $0.668^{* * *}$ & 0.043 \\
\hline Customers' cooperation & & & $0.447 * * *$ & 0.046 & $0.347 * * *$ & 0.044 \\
\hline Technological vigilance & & & & & $0.314^{* * *}$ & 0.015 \\
\hline Adjusted R-Squared & 0.286 & & 0.480 & & 0.539 & \\
\hline $\mathrm{F}$ & $129.266^{* * *}$ & & $233.037 * * *$ & & $276.148^{* * *}$ & \\
\hline
\end{tabular}

Table 8. Lineal regression on technological management 


\begin{tabular}{|c|c|c|c|c|}
\hline \multirow[b]{2}{*}{ Variables } & \multicolumn{2}{|c|}{ Model I } & \multicolumn{2}{|c|}{ Model II } \\
\hline & Beta & Std error & Beta & Std error \\
\hline Constant Controls & $-1.601 * * *$ & 0.133 & $-0.846^{* * *}$ & 0.114 \\
\hline Size & $1.497 * * *$ & 0.055 & $0.810^{* * *}$ & 0.050 \\
\hline Age & $0.010 * * *$ & 0.002 & $0.006^{* * *}$ & 0.001 \\
\hline $\mathrm{ROA}$ & 3.372 & 7.389 & 1.077 & 6.221 \\
\hline Medium-low tech industry & 0.137 & 0.070 & 0.047 & 0.059 \\
\hline Medium-high tech industry & $0.870^{* * *}$ & 0.080 & $0.501 * * *$ & 0.068 \\
\hline High tech industry & $1.282^{* * *}$ & 0.133 & $0.660^{* * *}$ & 0.113 \\
\hline Market stable & $-0.361^{* * *}$ & 0.078 & $-0.138^{* *}$ & 0.066 \\
\hline Market in recession & $-0.275^{* * *}$ & 0.088 & -0.110 & 0.074 \\
\hline Location & -0.077 & 0.117 & -0.057 & 0.098 \\
\hline Dummies years & Yes & & Yes & \\
\hline \multicolumn{5}{|l|}{ Main effects } \\
\hline Joint ventures & & & $0.260^{*}$ & 0.155 \\
\hline Suppliers' cooperation & & & $1.801 * * *$ & 0.086 \\
\hline Customers' cooperation & & & $1.081^{* * *}$ & 0.090 \\
\hline \multicolumn{5}{|l|}{ Technological vigilance } \\
\hline \multicolumn{5}{|l|}{ Technological management } \\
\hline Adjusted R-Squared & 0.316 & & 0.515 & \\
\hline $\mathrm{F}$ & $148.799 * * *$ & & $268.292 * * *$ & \\
\hline
\end{tabular}

Table 9. Lineal regression on internal R\&D effort

\begin{tabular}{|c|c|c|c|c|}
\hline \multirow[b]{2}{*}{ Variables } & \multicolumn{2}{|c|}{ Model III } & \multicolumn{2}{|c|}{ Model IV } \\
\hline & Beta & Std error & Beta & Std error \\
\hline Constant Controls & $-0.784^{* * *}$ & 0.113 & $-0.473^{* * *}$ & 0.097 \\
\hline Size & $0.691 * * *$ & 0.051 & $0.429 * * *$ & 0.045 \\
\hline Age & $0.006^{* * *}$ & 0.001 & $0.004^{* * *}$ & 0.001 \\
\hline $\mathrm{ROA}$ & 0.801 & 6.136 & 0.648 & 5.285 \\
\hline Medium-low tech. industry & 0.084 & 0.058 & $0.115^{* *}$ & 0.050 \\
\hline Medium-high tech industry & $0.538^{* * *}$ & 0.067 & $0.337^{* * * *}$ & 0.058 \\
\hline High tech industry & $0.653^{* * *}$ & 0.112 & $0.521^{* * *}$ & 0.096 \\
\hline Market stable & $-0.108^{*}$ & 0.065 & -0.032 & 0.056 \\
\hline Market in recession & -0.107 & 0.073 & -0.010 & 0.063 \\
\hline Location & -0.006 & 0.097 & -0.111 & 0.084 \\
\hline Dummies years & Yes & & Yes & \\
\hline \multicolumn{5}{|l|}{ Main effects } \\
\hline Joint ventures & 0.131 & 0.154 & $-0.260^{*}$ & 0.133 \\
\hline Suppliers' cooperation & $1.579 * * *$ & 0.087 & $0.887^{* * *}$ & 0.078 \\
\hline Customers' cooperation & $0.986^{* * *}$ & 0.089 & $0.626^{* * *}$ & 0.078 \\
\hline Technological vigilance & $0.298^{* * *}$ & 0.030 & -0.027 & 0.027 \\
\hline Technological management & & & $1.036 * * *$ & 0.030 \\
\hline Adjusted R-Squared & 0.528 & & 0.650 & \\
\hline $\mathrm{F}$ & $264.034 * * *$ & & $409.944 * * *$ & \\
\hline
\end{tabular}

Table 10. Lineal regression on internal R\&D effort 
With the aim of testing hypothesis $\mathrm{H} 6$ and $\mathrm{H} 7$ related with the relationship between organizational objectives, realized absorptive capacity and innovation, the negative binomial was used. The Akaike and Bayesiana information criterions, show in the Table 11, are measured of the relative quality of statistical models for a set of data. Given a set of candidate models for the data, the preferred model is the one with the minimum AIC or BIC value (Akaike, 1974; Schwarz, 1978).

The log-likelihood reported for the negative binomial regression is $-4054,430$. Compare this to the Poisson model. The log-likelihood reported for the Poisson regression is -9922,545. This is actually smaller than the log-likelihood for the negative binomial regression, which indicates that this Poisson regression does not offer an improvement over the negative binomial regression. Moreover, the Lagrange multiplier test is significant and indicates the fit of the negative binomial model.

The Model I of Table 11 only considers the influence of the control variables on a company's innovation. The main effects of cooperation activities, firm's absorptive capacity and internal R\&D efforts to Model II were added. The AIC and BIC value are lower in the Model II. The results of this model indicate that the impact of both types of absorptive capacity and internal R\&D effort on new products are significant ( $p, 0.01)$. With regard to cooperation activities, the results indicate that joint ventures and customers' cooperation have a positive and significant effect on new products. However, the results reflect a non-significant influence of suppliers' cooperation on innovation. Results show that the relevance of size variable and the positive and significant relation of market in recession. Finally, results also show the negative and significant relation of the different technological intensities of the sector.

\begin{tabular}{|c|c|c|c|c|}
\hline \multirow[b]{2}{*}{ Variables } & \multicolumn{2}{|c|}{ Model I } & \multicolumn{2}{|c|}{ Model II } \\
\hline & Beta & Std error & Beta & Std error \\
\hline Constant Controls & $-1.250^{* * *}$ & 0.151 & $-1.095^{* * *}$ & 0.167 \\
\hline Size & $1.289^{* * *}$ & 0.052 & $0.590^{* * *}$ & 0.062 \\
\hline Age & 0.002 & 0.001 & $-0.006^{* * *}$ & 0.001 \\
\hline $\mathrm{ROA}$ & 5.080 & 10.01 & 9.331 & 8.792 \\
\hline Low tech industry & $-0.917^{* * *}$ & 0.096 & $-0.779 * * *$ & 0.102 \\
\hline Medium-low tech. industry & $-1.247 * * *$ & 0.102 & $-1.527^{* * *}$ & 0.112 \\
\hline Medium-high tech industry & $-0.975^{* * *}$ & 0.103 & $-1.284 * * *$ & 0.110 \\
\hline Market stable & $-0.504^{* * *}$ & 0.064 & -0.017 & 0.073 \\
\hline Market in recession & $-0.122^{*}$ & 0.071 & $0.190^{* *}$ & 0.081 \\
\hline Location & $-0.601 * * *$ & 0.095 & $-0.717^{* * *}$ & 0.104 \\
\hline Dummies years & Yes & & Yes & \\
\hline \multicolumn{5}{|l|}{ Main effects } \\
\hline Joint ventures & & & $0.622 * * *$ & 0.132 \\
\hline Suppliers' cooperation & & & -0.054 & 0.085 \\
\hline Customers' cooperation & & & $0.287 * * *$ & 0.086 \\
\hline Technological vigilance & & & $0.060^{* *}$ & 0.030 \\
\hline Technological management & & & $0.356^{* * *}$ & 0.037 \\
\hline Internal R\&D effort & & & $0.237 * * *$ & 0.019 \\
\hline Likelihood ratio test (x2) & $1277.53^{* * * *}$ & & $2381.44 * * *$ & \\
\hline Log likelihood & -4606.380 & & -4054.430 & \\
\hline
\end{tabular}




\begin{tabular}{|c|c|c|c|c|}
\hline \multirow[b]{2}{*}{ Variables } & \multicolumn{2}{|c|}{ Model I } & \multicolumn{2}{|c|}{ Model II } \\
\hline & Beta & Std error & Beta & Std error \\
\hline Akaike information criteria (AIC) & 9236.760 & & 8144.859 & \\
\hline Bayesiana information criteria (BIC) & 9310.706 & & 8255.779 & \\
\hline Lagrange multiplier test & & & $2300.714 * * *$ & \\
\hline Pseudo R-Squared & & & 0.122 & \\
\hline
\end{tabular}

Table 11. Panel model analysis on innovation efficiency

\section{Discussion}

This study reveals important empirical results that make a significant contribution to clarifying the question about the influence of the types of absorptive capacity on innovation efficiency. First, with regard to the use of external sources of knowledge, the paper findings confirm that the relationship between the cooperation activities and firm's absorptive capacity, as stated H1 and H2. Furthermore, while suppliers and customers' cooperation are relevant actions to increase the internal R\&D effort, joint ventures and customers' cooperation are significant to the growth of new products. In the other side, joint ventures have a negative and significant influence in the organizational objectives in internal R\&D and suppliers' cooperation has no-significant effect on innovation.

Second, potential absorptive capacity, measurable as technological vigilance in this research, is a significant element of the internal R\&D effort when the realized absorptive capacity is out of the regression, as stated H4. Moreover, it appears as significant and positive influence on innovation models. Third, realized absorptive capacity, measurable as technological management in this study, capture all the explain power of the potential absorptive capacity when the internal R\&D effort was globally estimated, as $\mathrm{H} 3$ stated. The realized absorptive capacity is the most significant factor to explain the internal R\&D effort and influence highly on the new products, as H5 and H6 stated. Forth, the organizational objectives in internal R\&D, measurable as internal R\&D effort in this research, are pertinent elements on new products, as $\mathrm{H} 7$ stated.

Finally, the findings of this study should be noted as it is based on panel data models and are consistent with previous works, related with the absorptive capacity is a mediating instrument between technology alliance diversity and innovation (Lucena \& Roper, 2016), the significate interaction between external and internal knowledge sources on new products (Díaz-Díaz \& Saá-Pérez, 2014), the high positive impact of internal R\&D activities (Sánchez, Rosell \& García, 2013), the innovation process is not a sectoral phenomenon (Segarra-Ciprés et al. 2012), the importance of size variable (Revilla \& Fernández, 2012), the R\&D as a determinant of innovation, the low statistical significance of the age variable (Beneito et al., 2011) and the positive effects of technological knowledge assets on innovation process (Díaz-Díaz et al., 2006).

\section{Conclusion and Limitations}

In light of such insights from the knowledge management standpoint, this study considers it is necessary to analyze the typology of the absorptive capacity that can allow managers to understand an innovation efficiency process in the cooperation context and, therefore, make better decisions. The confluence of cooperation activities, firm's absorptive capacity and organizational objectives in internal R\&D will obtain higher innovative results.

Companies need external sources of knowledge to renew their knowledge. Thus, they need to look outside the company's boundaries and, as a final point, they need experience and resources in internal R\&D to be able to develop more innovation. The paper confirms that the potential and realized absorptive capacity comport and cause effects in diverse way. We provide evidence that types of absorptive capacity and internal R\&D effort serve as mediating mechanisms between cooperative activities and innovative performance. Our study advances the literature on absorptive capacity by showing how firms use their positions of technological vigilance and management to form their capabilities, and subsequently, to enhance innovation outcomes. This theoretical contribution completes the previous theoretical support found in the related literature (Table 12). 


\begin{tabular}{|c|c|c|}
\hline Articles & Absorptive capacity research themes & Methodology \\
\hline Aribi and Dupouët (2016) & Absorptive capacity as not linear process & Qualitative \\
\hline Grandinetti (2016) & Knowledge management in small and medium firms & Theoretical \\
\hline Lowik et al. (2016) & A holistic perspective on knowledge-intensive team & Qualitative \\
\hline Rezaei and Darwish (2016) & The antecedents of absorptive capacity & Theoretical \\
\hline Van der Heiden et al. (2016) & The necessitated absorptive capacity model & Theoretical \\
\hline Mariano and Walter (2015) & Review in the knowledge management literature & Review \\
\hline Ojo, Raman, Chong and Chong (2014) & Micro-level antecedents and social context & Theoretical \\
\hline Díaz-Díaz and Saá-Pérez (2014) & The internal and external sources of knowledge & Quantitative \\
\hline Denford (2013) & Absorptive capacity as a dynamic capability & Qualitative \\
\hline Andersén (2012) & Absorptive capacity and resource-based theory & Theoretical \\
\hline Tseng et al. (2011) & The influence of the learning process on innovation & Quantitative \\
\hline Wang and Han (2011) & Absorptive capacity as a moderating variable & Quantitative \\
\hline Noblet et al. (2011) & Absorptive capacity in terms of dynamic capabilities & Qualitative \\
\hline Volberda et al. (2010) & An integrative model of multilevel antecedents & Review \\
\hline Sun (2010) & Five critical knowledge management themes & Qualitative \\
\hline Todorova and Durisin (2007) & Inclusion of feedback loops in a dynamic model & Review \\
\hline Lane et al. (2006) & Five critical assumptions and model & Review \\
\hline Kale and Little (2005) & In an intra-organizational learning context & Qualitative \\
\hline Nieminen (2005) & In an inter-organizational knowledge transfer context & Theoretical \\
\hline Zahra and George (2002) & $\begin{array}{l}\text { Newer pieces to the construct and the potential and } \\
\text { realized absorptive capacity }\end{array}$ & Review \\
\hline Cohen and Levinthal (1990) & The seminal work on absorptive capacity & Quantitative \\
\hline
\end{tabular}

Table 12. Absorptive capacity in Knowledge Management and Intellectual Capital research

Regarding limitations, it would be interesting to extend the investigation to an-other innovation efficiency metrics as new organizational methods, new processes, new designs or new methods in the use of sales channels. Second, the agreement of cooperation activities constitutes an important decision for the firm's innovation. There may be further evidence of cooperation activities results such as alliances with universities and other research institutions, technological research projects with the EU, holdings in technological development firms and technological agreements with competitors, that are not included in this work and which of course would be interesting to analyze in future researches.

Third, once the typology has been performed, other types of absorptive capacity can be identified in the different inter and intra-organizational contexts because its construct not only depends on the individuals' analysis level, but also on the team characteristics, the social integration mechanisms or the long-term effects that influence communication between these individuals. Future studies would introduce the specific types of absorptive capacity or different analysis level to expand the research. Thus, there are opportunities for further research to contribute to the growing literature. The first could be a study of the detailed antecedents and its effects for each type of absorptive capacity. The second could be an explanation of knowledge sources and the capacity to absorb them in the context of the services sector. Finally, more theoretical development and discussion is recommended. 


\section{Declaration of Conflicting Interests}

The authors declared no potential conflicts of interest with respect to the research, authorship, and/or publication of this article.

\section{Funding}

The authors received no financial support for the research, authorship, and/or publication of this article.

\section{References}

Akaike, H. (1974). A new look at the statistical model identification. IEEE Transactions on Automatic Control, 19(6), 716-723. https://doi.org/10.1109/TAC.1974.1100705

Andersén, J. (2012). Protective capacity and absorptive capacity: Managing the balance between retention and creation of knowledge-based resources. Learning Organization, 19(5), 440-452.

https://doi.org/10.1108/09696471211239730

Aribi, A., \& Dupouët O. (2016). Absorptive capacity: A non-linear process. Knowledge Management Research \& Practice, 14, 15-26. https://doi.org/10.1057/kmrp.2014.17

Beneito, P., Rochina, M., \& Sanchis, A. (2011). La experiencia en I+D como factor determinante de la innovación. Papeles de Economía Española, 127, 89-104.

Capaldo, A., \& Messeni, A. (2015). Origins of knowledge and innovation in R\&D alliances: a contingency approach. Technology Analysis \& Strategic Management, 27(4), 461-483. https://doi.org/10.1080/09537325.2015.1011612

Cohen, M.W., \& Levinthal, D.A. (1989). Innovation and learning: the two faces of R\&D. The Economic Journal, 99(3), 569-596. https://doi.org/10.2307/2233763

Cohen, M.W., \& Levinthal, D.A. (1990). Absorptive capacity: A new perspective on learning and innovation. Administrative Science Quarterly, 35(1), 128-152. https://doi.org/10.2307/2393553

Denford, J.S. (2013). Building knowledge: Developing a knowledge-based dynamic capabilities typology. Journal of Knowledge Management, 17(2), 175-194. https://doi.org/10.1108/13673271311315150

Díaz-Díaz, N.L., \& Saá-Pérez, P. (2014). The interaction between external and internal knowledge sources: An open innovation view. Journal of Knowledge Management, 18(2), 430-446. https://doi.org/10.1108/JKM-07-2013-0257

Díaz-Díaz, N.L., Aguilar-Díaz, I., \& Saá-Pérez, P. (2006). Technological knowledge assets in industrial firms. R\&D Management, 36(2), 189-203. https://doi.org/10.1111/j.1467-9310.2006.00425.x

Fixson, S.K., \& Lee, W.H. (2012). Shifting grounds: how industry emergence changes the effectiveness of knowledge creation strategies - the case of the US automotive airbag industry. Technology Analysis \& Strategic Management, 24(1), 1-19. https://doi.org/10.1080/09537325.2012.643557

Fukugawa, N. (2015). How can learning efficiency be improved in teaching economics in English as a foreign language? International Journal Knowledge and Learning, 10(1), 44-59. https://doi.org/10.1504/IJKL.2015.071053

Grandinetti, R., (2016). Absorptive capacity and knowledge management in small and medium enterprises. Knowledge Management Research \& Practice, 14, 159-168. https://doi.org/10.1057/kmrp.2016.2

Hagemeister, M., \& Rodríguez-Castellanos, A. (2010). Organisational capacity to absorb external R\&D: industrial differences in assessing intellectual capital drivers. Knowledge Management Research \& Practice, 8(2), 102-111. https://doi.org/10.1057/kmrp.2010.5

Kale, D., \& Little, S. (2005). Knowledge generation in developing countries: A theoretical framework for exploring dynamic learning in high technology firms. Electronic Journal of Knowledge Management, 3(2), 87-96.

Lane, P., Koka, B., \& Pathak, S. (2006). The reification of absorptive capacity: A critical review and rejuvenation of the construct. Academy of Management Review, 31(4), 833-863. https://doi.org/10.5465/AMR.2006.22527456 
Lowik, S., Kraaijenbrink, J., \& Groen, A. (2016). The team absorptive capacity triad: A configurational study of individual, enabling, and motivating factors. Journal of Knowledge Management, 20(5), 1083-1103.

https://doi.org/10.1108/JKM-11-2015-0433

Lucena, A., \& Roper, S. (2016). Absorptive capacity and ambidexterity in R\&D: Linking technology alliance diversity and firm innovation. European Management Review, 13(3), 159-178. https://doi.org/10.1111/emre.12074

Mariano, S., \& Walter, C. (2015). The construct of absorptive capacity in knowledge management and intellectual capital research: content and text analyses. Journal of Knowledge Management, 19(2), 372-400.

https://doi.org/10.1108/JKM-08-2014-0342

Martelo-Landroguez, S., \& Cegarra-Navarro, G.-J. (2014). Linking knowledge corridors to customer value through knowledge processes. Journal of Knowledge Management, 18(2), 342-365. https://doi.org/10.1108/JKM-07-2013-0284

Messeni, A., Rotolo, D., \& Albino, V. (2012). The Impact of old technologies on innovation: The case of the US biotech. Industry. Technology Analysis \& Strategic Management, 24(5), 453-466.

https://doi.org/10.1080/09537325.2012.674668

Nieminen, H. (2005). Organizational receptivity. Understanding the inter-organizational learning ability. Electronic Journal of Knowledge Management, 3(2), 107-118.

Noblet, J.P., Simon, E., \& Parent, R. (2011). Absorptive capacity: A proposed operationalization. Knowledge Management Research \& Practice, 9(4), 367-377. https://doi.org/10.1057/kmrp.2011.26

O'Brian, R.M. (2007). A caution regarding rules of thumb for variance inflation factors, Quality and Quantity, 41(5), 673-690. https://doi.org/10.1007/s11135-006-9018-6

Ojo, A.O., Raman, M., Chong, S.C., \& Chong, C.W. (2014). Individual antecedents of ACAP and implications of social context in joint engineering project teams: a conceptual model. Journal of Knowledge Management, 18(1), 177-193. https://doi.org/10.1108/JKM-08-2013-0332

Ojo, A.O., Raman. M., \& Chong, C.W. (2016). Individual differences and potential absorptive capacity in joint project teams in the Nigerian upstream oil industry. VINE Journal of Information and Knowledge Management Systems, 46(1), 45-63. https://doi.org/10.1108/VJIKMS-08-2014-0050

Paulsen, J.M., \& Hjertø, K.B. (2014). Exploring individual-level and group-level levers for inter-organizational knowledge transfer. The Learning Organization, 21(4), 274-287. https://doi.org/10.1108/TLO-09-2013-0044

Revilla, A.J., \& Fernández, Z. (2012). The relation between firm size and R\&D productivity in different technological regimes. Technovation, 32(11), 609-623. https://doi.org/10.1016/j.technovation.2012.06.004

Rezaei, M., \& Darwish, T.K. (2016). Antecedents of absorptive capacity: A new model for developing learning processes. The Learning Organization, 23(1), 77-91. https://doi.org/10.1108/TLO-04-2015-0026

Roberts, N., Galluch, P., Dinger, M., \& Grover, V. (2012). Absorptive capacity and information systems research: Review, synthesis, and directions for future research. MIS Quarterly, 36(2), 625-648.

Sánchez, P., Rosell, J., \& García, J.M. (2013). Innovation as a driver of absorptive capacity from foreign direct investment in Spanish manufacturing firms. Procedia - Social and Behavioral Sciences, 75, $236-245$.

https://doi.org/10.1016/j.sbspro.2013.04.027

Schwarz, G.E. (1978). Estimating the dimension of a model. Annals of Statistics, 6(2), 461-464.

https://doi.org/10.1214/aos/1176344136

Segarra-Ciprés, M., Bou-Llusar, J.C., \& Roca-Puig, V. (2012). Exploring and exploiting external knowledge: The effect of sector and firm technological intensity. Innovation-Management Policy \& Practice, 14, 192-206.

https://doi.org/10.5172/impp.2012.14.2.203

Sun, P. (2010). Five critical knowledge management organizational themes. Journal of Knowledge Management, 14(4), 507-523. https://doi.org/10.1108/13673271011059491 
Todorova, G., \& Durisin, B. (2007). Absorptive capacity: Valuing a reconceptualization. Academy of Management Review, 32(3), 774-786. https://doi.org/10.5465/AMR.2007.25275513

Tseng, C.Y., Pai, D.C., \& Hung, C.H. (2011). Knowledge absorptive capacity and innovation performance in KIBS. Journal of Knowledge Management, 15(6), 971-983. https://doi.org/10.1108/13673271111179316

Van der Heiden, P., Pohl, C., Mansor, S., \& Van Genderen, J. (2016). Necessitated absorptive capacity and metaroutines in international technology transfer: A new model. Journal of Engineering and Technology Management, 41, 65-78. https://doi.org/10.1016/j.jengtecman.2016.07.001

Volberda, H.W., Foss, N.J., \& Lyles, M.A. (2010). Absorbing the concept of absorptive capacity: How to realize its potential in the organization field. Organization Science, 21(4), 931-951. https://doi.org/10.1287/orsc.1090.0503

Wang, C., \& Han, Y. (2011). Linking properties of knowledge with innovation performance: the moderate role of absorptive capacity. Journal of Knowledge Management, 15(5), 802-819. https://doi.org/10.1108/13673271111174339

Yoo, S.-J., Sawyerr, O., \& Tan, W.-L. (2015). The impact of exogenous and endogenous factors on external knowledge sourcing for innovation: The dual effects of the external environment. Journal of High Technology Management Research, 26, 14-26. https://doi.org/10.1016/j.hitech.2015.04.002

Zahra, S.A., \& George, G. (2002). Absorptive capacity: A review, reconceptualization, and extension. Academy of Management Review, 27(2), 185-203.

Journal of Industrial Engineering and Management, 2018 (www.jiem.org)

\section{(ब) $(\Theta \otimes$}

Article's contents are provided on an Attribution-Non Commercial 4.0 Creative commons International License. Readers are allowed to copy, distribute and communicate article's contents, provided the author's and Journal of Industrial Engineering and Management's names are included. It must not be used for commercial purposes. To see the complete license contents, please visit https://creativecommons.org/licenses/by-nc/4.0/. 